\title{
Cultural Differences in the Overtness and Covertness of Positive and Negative Emotion
}

\author{
Chelsea Hughes ${ }^{1}$, Derrick Wirtz ${ }^{1}$, \& Christie Scollon² \\ ${ }^{1}$ East Carolina University \& ${ }^{2}$ Singapore Management University
}

\begin{tabular}{|c|}
\hline Introduction \\
\hline $\begin{array}{l}\text { Affect Display and Display Rules } \\
\text { The idea of display rules was first introduced by Ekman and } \\
\text { Frieson (1969), who defined them as scripts for controlling } \\
\text { affect displays. This included three forms of affect } \\
\text { regulation: savoring, dampening, or maintaining. The } \\
\text { trends of these rules vary between cultures, depending on } \\
\text { what is defined as acceptable or unacceptable expression } \\
\text { (Matsumoto, Kasri, \& Kooken, 1999). }\end{array}$ \\
\hline $\begin{array}{l}\text { Emotion Preferences of Americans (Individualistic) } \\
\text { - Prevailing script of maximizing positive emotion and } \\
\text { Kurokawiza, 2000). } \\
\text { - Individuals encouraged to overtly express feeling and } \\
\text { exaggerate its strength (Matsumoto, Takeuchi, } \\
\text { Andayani, Kouznetsova, \& Krupp, 1998). } \\
\text { - Values and endorses uniqueness and separateness } \\
\text { (Markus \& Kitayama, 1991). } \\
\text { "The squeaky wheel gets the grease" (Goleman, 1990). }\end{array}$ \\
\hline $\begin{array}{l}\text { Emotion Preferences of East Asians (Collectivistic) } \\
\text { - Values the group above the individual. } \\
\text { - } \text { - Emomotes harmony and unity and suppresses individual } \\
\text { relationship between the self and the group, so affect } \\
\text { displays are highly controlled (Mesquita, 2001). } \\
\text { - Seek a balance between positive and negative emotion } \\
\text { (Peng \& Nisbett, 1999). } \\
\text { - Less supportive of overt emotion expression when } \\
\text { Matsumoto, Takeuchi, Andayani, Kouznetsova, \& Krupp, } \\
\text { 1998). } \\
\text { "The nail that sticks out gets hammered down" } \\
\text { (Goleman, 1990). }\end{array}$ \\
\hline $\begin{array}{l}\text { Hypotheses } \\
\text { (H1) In both cultures, negative emotions will occur } \\
\text { when alone more often than positive emotions. } \\
\text { (H2a) Americans will hide negative emotions } \\
\text { significantly more than positive emotions. } \\
\text { (H2b) Singaporeans will hide positive emotions more } \\
\text { frequently than Americans. } \\
\text { (H3a) Americans will discuss positive emotions with } \\
\text { others significantly more than negative emotions. } \\
\text { (H3b) Singaporeans will discuss positive emotions with } \\
\text { others significantly less than Americans. } \\
\text { (H3c) Americans will discuss emotional experiences } \\
\text { more often than Singaporeans. }\end{array}$ \\
\hline
\end{tabular}

\begin{tabular}{l} 
Method \\
\hline \multicolumn{1}{|c|}{ Metricipants } \\
This study consisted of volunteer participants from ECU (a total of 446 students) \\
and from Singapore Management University (a total of 43 students). These \\
students were able to access the study using online survey software. \\
The Surveys \\
- Section 1: memory recall of six recent memories, three negative and three \\
positive, in a counterbalanced order (see Jordan et al, 2011). The survey asked \\
for the intensity of the emotion, who was present, whether or not they hid \\
their emotion, and with whom they spoke about it afterwards. \\
- Section 2: 12 question survey designed for this study, The Perceptions of \\
Emotional Behavior Survey, gauges perceptions of emotional behavior. \\
- Section 3: Satisfaction with Life Survey (SWLS), the Subjective Happiness Scale \\
(SHS), and the UCLA Loneliness Scale (UCLALS).
\end{tabular}
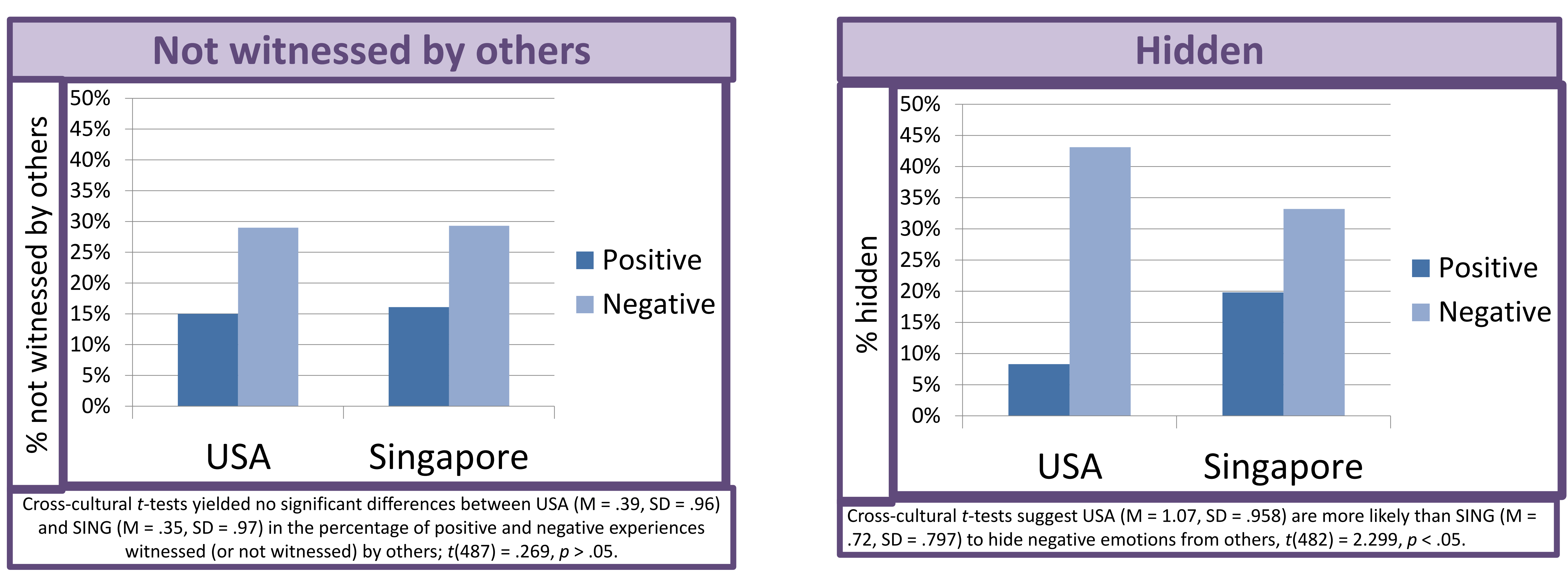

\section{Results}

USA: Negative emotions occur in solitude $29 \%$ of the time; positive emotions occur in solitude $15 \%$ of the time; $t(445)$ $=8.58, p<.05$.

SING: Negative emotions occur in solitude $29.3 \%$ of the time; positive emotions occur in solitude $16.1 \%$ of the time; $t(42)=2.34, p<.05$.

\section{*The Perceptions of Emotional Behavior Survey}

Singaporeans agreed significantly more than Americans did with statements gauging their concern for their emotion's impact on the peer group: "If I share my worries, I worry that I will burden others with my sadness" (USA: M=4.43, $\mathrm{SD}=1.66$; $\mathrm{SING}: \mathrm{M}=5.44, \mathrm{SD}=1.26 ; t(486)=-3.875, p<.05)$ and "If I express my happiness for my successes, I worry th may make others feel badly about themselves," (USA: $M=4.1$, $S D=1.65$; SING: $M=4.9, S=1.4, t(486)=-3.212, p<.05$

Singaporeans $(M=4.98, S D=1.33)$ also agreed significantly more than Americans $(M=4.12, S D=1.69)$ did with the statement, "I don't mind failure, as long as I learned something from it," $t(487)=-3.232, p<.05$

Americans ( $M=5.30, S D=1.58$ ) agreed significantly more than Singaporeans $(M=4.47, S D-1.79)$ did with the statement, "I feel comfortable sharing my worries and complaints with my family" $t(486)=3.252, p<.05$

The SWLS, no significant differences: USA (M = 4.64, SD = .812) and SING $(M=4.53, \mathrm{SD}=.79), t(486)=.896, p>.05$. The SHS, no significant differences: USA ( $M=5.11, S D=1.14)$ and $\operatorname{SING}(M=4.82, S D=1.10), t(389)=1.52, p>.05$. The UCLALS, $t$ test indicated that SING ( $M=2.4, S D=.50$ ) reported higher levels of loneliness than USA ( $M=2.64, S D=$ $.63) ; t(468)=2.39, p<.05$

\section{Discussion}

Participants of both cultures reported that negative experiences occur cultural consistency regrding the overtness do positive experiences, indicating experiences. Yet we see considerable differences in the way these emotional experiences are handled. Data analysis showed that Singaporeans dampen finding was indicated by the responses to the family-oriented question from Perceptions of Emotional Behavior survey: "I feel comfortable sharing my Worries and complaints with my family.

Overall, the study found strong differences in the display and treatment of motional experiences, which were consistent with the display rules of each

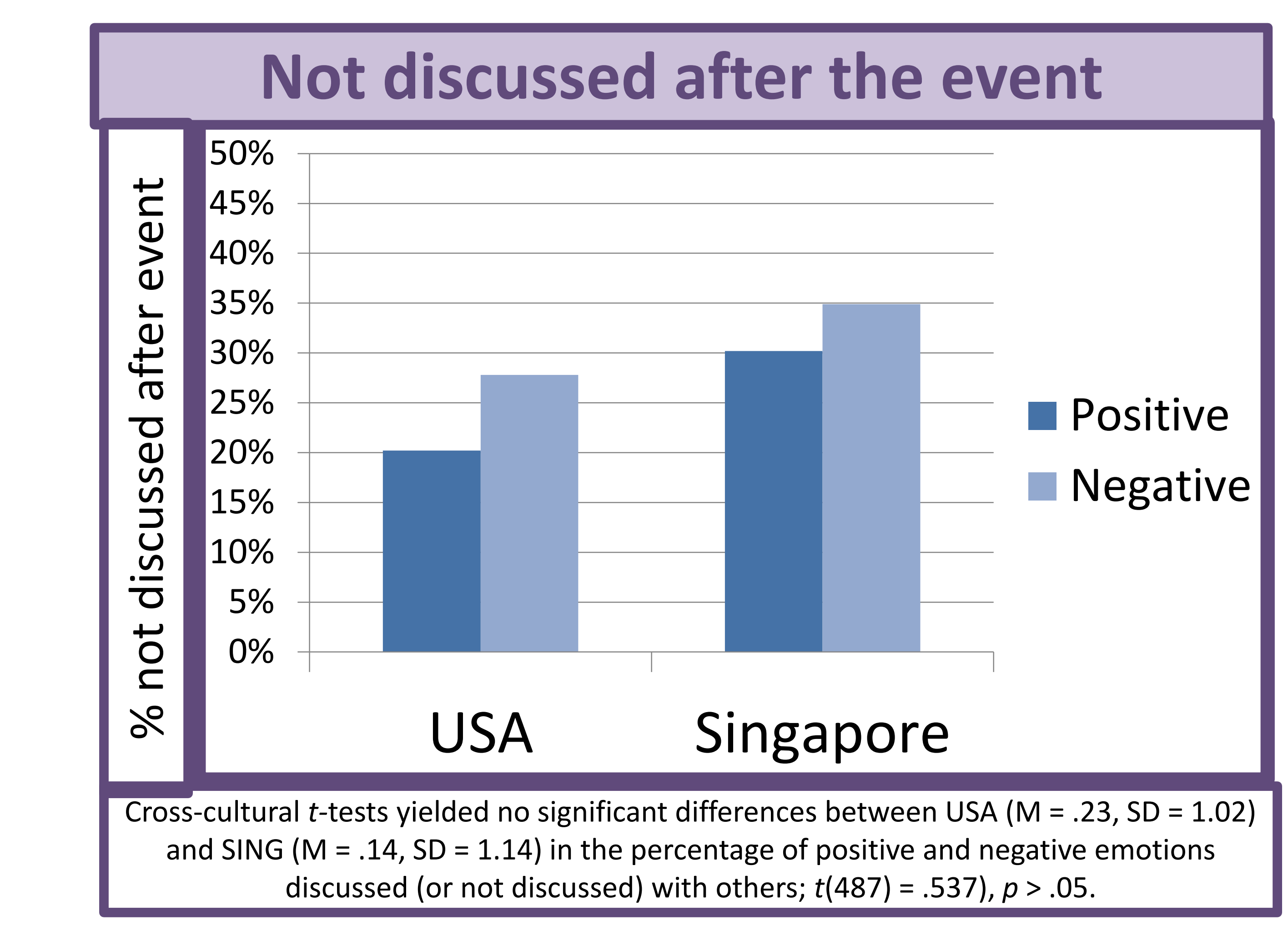

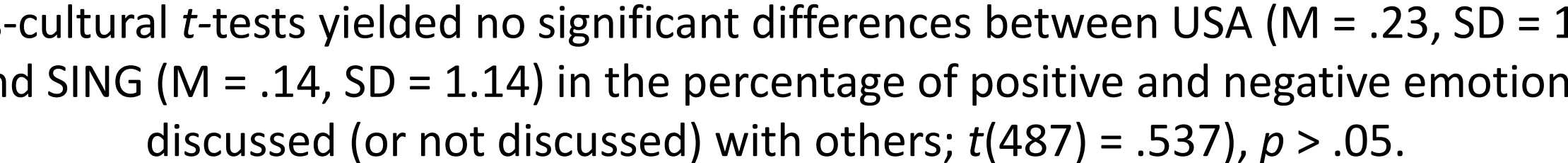

